\title{
Epidemiological profile of psychiatric illnesses in the province of Taza, Morocco: case of a study on a schizophrenic sub- population in the Ibn Baja Hospital
}

\author{
El Hassan Ouanouche ${ }^{1 *}$, Hasnae Lamine ${ }^{2}$, Asmae Tliji ${ }^{3}$, Hajar Hourmattallah³ ${ }^{3}$ Ali Ouichou?',
} Aboubaker El Hessni ${ }^{1}$ and Abdelhalim Mesfioui ${ }^{1}$

\begin{abstract}
Aim: The objective of this study is to assess the prevalence of major psychiatric disorders and to plot some characteristics of the schizophrenic sub-population in the study area.

Methods: We present the results of a retrospective study on psychiatric illnesses listed at the level of the psychiatric department at the Ibn Baja Hospital in the province of Taza (Morocco), involving a sample of 3803 patients aged 18 years and over between 2006 and 2016.

Results: The results obtained show that the average age of our sample is $33 \pm 10.5$ years and that schizophrenia is the most pronounced psychiatric disorder with a prevalence of $69.9 \%$, followed by bipolar disorder (8.4\%), manic state (8.3\%), major depression (5.8\%), epilepsy (3.7\%), dementia (2.5\%), and drug addiction (1.5\%). The predominance of the workforce for all psychiatric disorders was significantly in favor of males $(P=0.000)$ with an M/F sex ratio of 4.9. Most patients were from urban areas $77.1 \%$, compared with $22.9 \%$ from rural areas, with a predominance of males $(P<0.001)$. Schizophrenia disease is the most predominant in the region with a prevalence of $1.6 \%$ and affects $83 \%$ of men versus $17 \%$ of women with a M/F sex ratio value of 5.6 in favor of men $(P=0.000)$.

Conclusion: In our region of study, as everywhere else in the world, the prevalence of psychiatric diseases on the one hand, and schizophrenia on the other hand, seems to be worrying, thus requiring more vigilance on the part of public health workers in general and mental health workers.
\end{abstract}

Keywords: Retrospective study, Psychiatric diseases, Prevalence of schizophrenia

\section{Introduction}

Mental disorders, according to the World Health Organization (WHO), are clinically significant conditions characterized by a change in thought mode, mood, or behavior associated with mental distress and/or mental impairment functions affecting mental health. The World Health Report, carried out by the WHO in 2001, revealed

\footnotetext{
* Correspondence: elhassanouanouche@gmail.com

'Biology and Health Laboratory, Department of Biology, Faculty of Sciences, University Ibn Tofail, FSK-Kenitra, Kenitra, Morocco

Full list of author information is available at the end of the article
}

that 450 million people suffer from mental disorders. The same organization predicts that $25 \%$ of the world's population will have a mental disorder in their lifetime. Thus, psychiatric diseases have become an international concern and are the second leading cause of morbid mortality in developing countries $[1,2]$. The national prevalence of mental disorders and drug addiction in Morocco is $48.9 \%$ based on the results of an epidemiological survey carried out by the Moroccan Ministry of Health in collaboration with the World Health Organization 2005 [3]. Thus, whether in the world or in Morocco, mental disorders do

\section{Springer Open}

(c) The Author(s). 2021 Open Access This article is licensed under a Creative Commons Attribution 4.0 International License, which permits use, sharing, adaptation, distribution and reproduction in any medium or format, as long as you give appropriate credit to the original author(s) and the source, provide a link to the Creative Commons licence, and indicate if changes were made. The images or other third party material in this article are included in the article's Creative Commons licence, unless indicated otherwise in a credit line to the material. If material is not included in the article's Creative Commons licence and your intended use is not permitted by statutory regulation or exceeds the permitted use, you will need to obtain permission directly from the copyright holder. To view a copy of this licence, visit http://creativecommons.org/licenses/by/4.0/. 
not yet benefit from the growing interest in infectious diseases or so-called non-communicable diseases (cardiovascular diseases, cancers, etc.). However, they are a major public health problem in addition to the economic burden they are responsible for.

Faced with this alarming situation, and due to the lack of epidemiological studies specific to Taza region as in most of the regions of Morocco, our study, the first of its kind, comes to give more details about the prevalence of the different psychiatric diseases encountered in the region of Taza (Morocco). Our study will be a reference for further studies in view of our sample size and our results relevance.

\section{Methods}

The present study is based on a retrospective survey with descriptive and analytical aims, within the regional psychiatric service of the Ibn-Baja general Hospital in the city of Taza (Morocco). The survey was based on the analysis of archived case data from 3803 patients who had visited the psychiatric department of Ibn-Baja general Hospital. Thus, the study covers a period from 1 January 2006 to 2 December 2016. The data collected relate to age, sex, origin (rural or urban) and length of stay. Next, the retrospective study continues with a profile-covering the same aspects-of the population suffering only from schizophrenia represented by 2657 patients. The diagnosis of psychiatric disorders being made based on DSM IV criteria

The data statistical analysis was performed by IBM SPSS Statistics version 22.0. The significance threshold is set at $5 \%$.

The procedures followed complied with the ethical standards of the competent commission for human experimentation and with the principles of the Declaration of Helsinki. Written informed consent was obtained from all participants and authorization was obtained from the Ethics Committee of the CED (CENTRE D'ETUDES DOCTORALES-FSK) of the Kenitra Faculty of Science and the provincial delegation of the Ministry of Public Health 09/2015.

\section{Results \\ Overall sample}

Figure 1 shows that the psychiatric patient population appears to be changing exponentially and is doubling towards the end of the period identified by our study. Little non-significant fluctuation between 2013 and 2016, with a maximum of visits in 2015 by 472 patients or $12.4 \%$ of the total number of visitors 3803 . In contrast, the lowest number of visitors in 2006 was no more than $5.4 \%$ or 207 patients, with a significant difference between the two sexes in favors of men $(P<0.001)$.

Table 1 summarizes the characteristics of the 3803 patients in our study. The average age of our overall sample is $33 \pm 10.5$ years; the age range most affected by psychiatric disorders is between 19 and 90 years. With significant predominance in males $82.9 \%$ versus $17.1 \%$ in females $(P=0.000)$, the sex $\operatorname{ratio}(\mathrm{M} / \mathrm{F})$ is $4.9 .77 .1 \%$ of cases lived in an urban environment, the remaining $22.9 \%$ are from rural areas, the predominance is always in favor of men $(P<0.001)$. Our study also showed that schizophrenia disease is the most common disorder among the various disorders listed in the study area, with a percentage of $69.9 \%$, followed by bipolar disorder $8.4 \%$, manic condition $8.3 \%$, major depression $5.8 \%$, epilepsy $3.7 \%$ (patients suffering from epilepsy often have psychiatric amenities, which explains why they are cared

\section{EFFECTIFS}

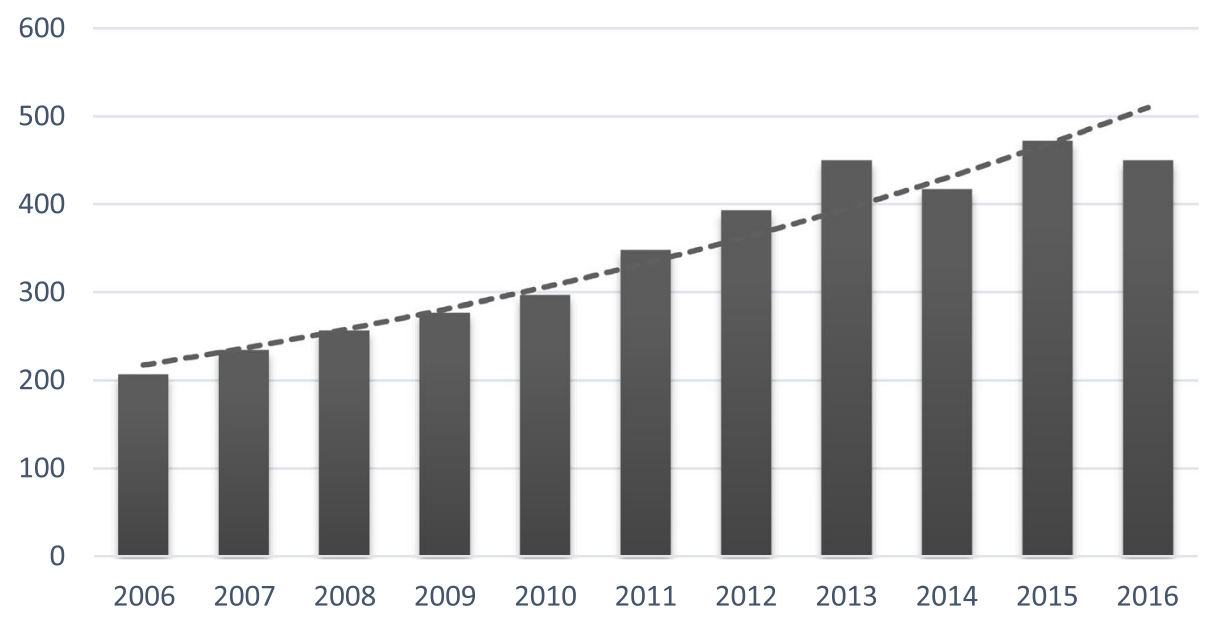

Fig. 1 Annual evolution of the number of patients visiting the psychiatric ward of Ibn Baja Taza Hospital between 2006 and 2016 (---, trend curve) 
Table 1 Characteristics of the overall sample in the study area

\begin{tabular}{|c|c|c|c|c|c|c|}
\hline Variables & & Staff & frequency & Men (\%) & Woman (\%) & $P(a=0.05)$ \\
\hline Sex & & 3803 & $100 \%$ & $82.9 \%$ & $17.1 \%$ & $P<0.001$ \\
\hline \multirow[t]{8}{*}{ Age range (years) } & [10-19] & 183 & 4.8 & 74.32 & 25.68 & $P=0.000$ \\
\hline & [20-29] & 1430 & 37.6 & 85.38 & 14.62 & \\
\hline & [30-39] & 1244 & 32.7 & 84.15 & 15.85 & \\
\hline & [40-49] & 627 & 16.5 & 81.15 & 18.85 & \\
\hline & [50-59] & 247 & 6.5 & 77.33 & 22.67 & \\
\hline & [60-69] & 49 & 1.3 & 72.55 & 27.45 & \\
\hline & [70-79] & 19 & .5 & 55.55 & 44.45 & \\
\hline & [80-89] & 4 & .1 & 57 & 25 & \\
\hline \multirow[t]{2}{*}{ Provenance } & Urban areas & 2932 & 77.1 & 54 & 41 & $P<0.001$ \\
\hline & Rural areas & 871 & 22.9 & 46 & 58 & \\
\hline \multirow[t]{7}{*}{ Diagnosis } & Schizophrenia & 2658 & 69.9 & 84.87 & 15.13 & $P=0.000$ \\
\hline & Bipolar disorder & 319 & 8.4 & 82.81 & 17.19 & \\
\hline & Manic state & 316 & 8.3 & 81.27 & 18.73 & \\
\hline & Major Depression & 221 & 5.8 & 71.69 & 28.31 & \\
\hline & Epilepsy & 141 & 3.7 & 80 & 20 & \\
\hline & Dementia & 95 & 2.5 & 64.21 & 35.79 & \\
\hline & Drug addiction & 57 & 1.5 & 82.46 & 17.54 & \\
\hline \multirow[t]{9}{*}{ Length of stay (days) } & {$[0-29]$} & 3252 & 85.5 & 83.69 & 16.31 & $P=0.000$ \\
\hline & [30-59] & 338 & 8.9 & 72.11 & 27.89 & \\
\hline & [60-89] & 80 & 2.1 & 82.72 & 17.28 & \\
\hline & [90-119] & 23 & 6 & 75 & 25 & \\
\hline & [120-149] & 4 & .1 & 100 & 00 & \\
\hline & [150-179] & 23 & 6 & 95.24 & 4.76 & \\
\hline & [180-209] & 53 & 1.4 & 94.44 & 5.56 & \\
\hline & [210-239] & 8 & .2 & 83.33 & 16.67 & \\
\hline & [240-269] & 27 & .7 & 96.15 & 3.85 & \\
\hline
\end{tabular}

for by the said department.), dementia $2.5 \%$, and then addiction with a proportion of $1.5 \%$. Most patients do not exceed 1 month of hospitalization within the hospital structure $85.5 \%$, with a significant predominance in men $83.69 \%$ compared to women $(P=0.000)$.

\section{Sample of schizophrenic patients}

Figure 2 shows that the trend curve in the patients' number with schizophrenia who visit the psychiatric department seems to be divided into two phases. Over the period from 2006 to 2010, there was a gradual decline of 5.8\%. From 2011 must note an exponential increase until 2016 with a percentage of $16.1 \%$, a value doubling that of the first phase, with a significant predominance of the male population compared to women $(P=0.000)$.

The mean age of our schizophrenic sample is $31 \pm 12$ years, the age group most affected by schizophrenia is between 20 and 90 years with non-significant predominance in males $84.9 \%$ of males versus $15.1 \%$ in females
$(P=0.775)$, the sex ratio $(\mathrm{M} / \mathrm{F})$ is $5.6 .69 .80 \%$ of cases lived in urban areas, and the remaining $30.20 \%$ are from rural areas with a non-significant difference between men and women $(P=0.250)$. Our study also showed that the length of stay of the parties in the hospital service does not exceed 1 month for most cases $87.2 \%$, the men extend the most represented $85.30 \%$ with a significant difference ( $" P=0.009$ ) (Table 2).

\section{Discussion}

\section{For the overall sample}

According to our study, our socio-demographic results are very similar to global data. Indeed, $82.9 \%$ of sick patients are men, 69\% in Algeria [4], 68.8\% in Israel [5], and $63.8 \%$ in France [6]. At the national level, this similarity is not clear $47.2 \%$ [3] with $77.7 \%$ in Casablanca [7], $46.4 \%$ in Kenitra [8], and $37.53 \%$ in Tetouan [9]. The high sex ratio in favor of men (4.9) could give the illusion that men are the most affected by psychiatric 


\section{EFFECTIFS}

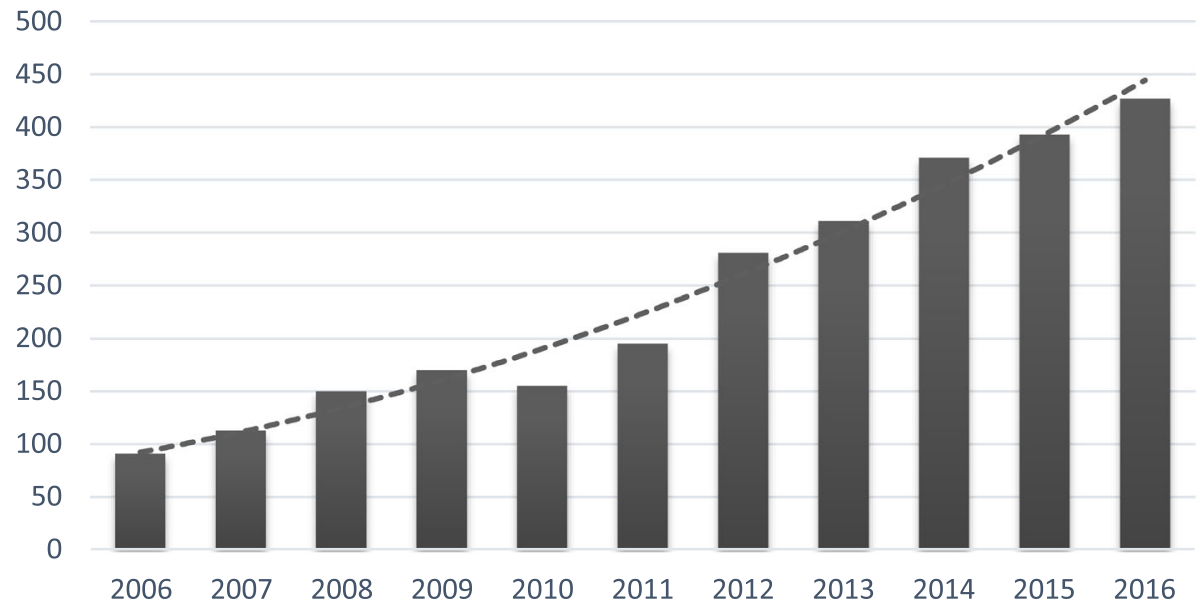

Fig. 2 Annual evolution of the number of schizophrenic patients visiting the psychiatric ward of the Ibn Baja Taza Hospital between 2006 and 2016 (---, trend curve)

disorders, something that is not fair if we take into account the social position of women and the traditional customs that mark the Moroccan population in general and the population of our study region in particular. The family hierarchy that made the man first worried about his health state and benefited from medical care.
Stigma can also explain these differences, as the image of women in the population is more sensitive than that of men. All these factors can explain the significant difference between the number of men and women who appear before public health services and a psychiatric center.

Table $\mathbf{2}$ Characteristics of the schizophrenic sample in the study area

\begin{tabular}{|c|c|c|c|c|c|c|}
\hline Variables & & Staff & frequency & Men (\%) & Woman (\%) & $P(\alpha=0.05)$ \\
\hline Sex & & 2657 & $100 \%$ & $84.9 \%$ & $15.1 \%$ & $P=0.000$ \\
\hline \multirow[t]{9}{*}{ Age range (years) } & [10-19] & 141 & 5.30 & 84.40 & 15.60 & $P=0.775$ \\
\hline & [20-29] & 1012 & 38.10 & 86.26 & 13.74 & \\
\hline & [30-39] & 874 & 32.90 & 83.07 & 16.93 & \\
\hline & [40-49] & 428 & 16.10 & 84.80 & 15.20 & \\
\hline & [50-59] & 151 & 5.70 & 86.70 & 13.30 & \\
\hline & {$[60-69]$} & 35 & 1.32 & 82.90 & 17.10 & \\
\hline & [70-79] & 13 & 0.50 & 84.60 & 15.40 & \\
\hline & {$[80-89]$} & 2 & 0.07 & 100 & 0 & \\
\hline & [90-99] & 1 & 0.04 & 100 & 0 & \\
\hline \multirow[t]{2}{*}{ Provenance } & Urban areas & 1855 & 69.80 & 56.10 & 43.90 & $P=0.250$ \\
\hline & Rural areas & 802 & 30.20 & 66.10 & 33.90 & \\
\hline \multirow[t]{9}{*}{ Length of stay (days) } & {$[0-29]$} & 2317 & 87.2 & 85.30 & 14.70 & $P<0.009$ \\
\hline & [30-59] & 203 & 7.64 & 76.80 & 23.20 & \\
\hline & {$[60-89]$} & 43 & 1.62 & 86.00 & 14.00 & \\
\hline & [90-119] & 15 & 0.56 & 73.00 & 27.00 & \\
\hline & [120-149] & -- & -- & -- & -- & \\
\hline & [150-179] & 16 & 0.60 & 6.00 & 94.00 & \\
\hline & [180-209] & 39 & 1.47 & 92.30 & 7.70 & \\
\hline & [210-239] & 0 & 00 & 00 & 00 & \\
\hline & [240-269] & 24 & 0.90 & 95.83 & 4.17 & \\
\hline
\end{tabular}


The similarity of our results with those of the global data is also evident in the age factor. Indeed, the average age of our overall sample, rather young 31 years, is like that found in Casablanca 31.5 years [7]. On an international level, the difference observed in Chile 36.2 years [10] and in Switzerland 44 years can only be relayed to the youth of the Moroccan population [7]. The age group most affected by psychiatric disorders ranges between 20 and 40 years with a peak between 20 and 30 years, a pivotal period in life, in which most social ties are formed, patients would be deprived of experience and interaction with their surroundings, which would cause them real handicaps for social integration. The urbanity rate in the region of our study is expected to be $71.1 \%$, This result is consistent with the result of the national survey [11]. The work of Peen et al. [12] on 20 populations showed the dominance of psychiatric disorders in urban settings. In addition, a study conducted in rural and urban Canada found that urban origin was a risk factor for psychiatric disorders [13]. This study questioned the lack of social support in urban areas as opposed to rural areas where interdependence prevails over individuals; these same factors could be involved in the explanation of the high rate $(71.1 \%)$ of psychiatric diseases among urban respondents (Table 1). The length of stay in our study area did not exceed 1 month for most patients. This situation can be explained by the limitation of the capacity of and of the staff of the said hospital structure and which does not exceed about thirty beds, situation like that of Casablanca [7]. This is another challenge for authorities to improve the capacity and quality of care for patients. The annual cadence of the number of new cases is quite high; this is visible in the trend curve that shows an exponential aspect. This result confirmed by several studies is a real wake-up call for the government and the Ministry of Public Health for rapid action is multifaceted to remedy this scourge.

\section{For the schizophrenic sample}

Schizophrenia is a serious chronic mental illness, characterized by the loss of contact with reality (Bleuler 1908): false perceptions, false beliefs, abnormalities of thought, emotional blunders, decreased motivation, disorders of social functioning, and source of socio-professional disintegration and emotional isolation [14]. Schizophrenia is the most incriminating mental disorder in the transition to the act of homicide [15], but also suicidal [16, 17]. It occurs most often in late adolescence or early adulthood, which explains why $71 \%$ of the schizophrenic cases in our sample were between the ages of 20 and 40 . As in our overall sample, the sex ratio value (5.6) is not an exception to the global data that suggest schizophrenia affects as many women as men in the general population [2]. The urbanity that characterizes our sample is consistent with most epidemiological studies that found a higher rate of schizophrenic subjects in urban areas, about twice as high as rural areas $[18,19]$. Urbanity can be considered a "marker" of the risk of schizophrenia. The prevalence of schizophrenia in the region over the study period (11 years) is estimated to be approximately $0.5 \%$; the general population in the region being 528,419 according to the last tightening between 2006 and 2016 (https://www. hcp.ma/region-oriental/docs/RGPH2014/29_04_2015.pdf).

This result is easily in line with international values, in fact between 0.5 and $2 \%$ in France [20], the global prevalence in the general population identified by the World Health Organization is $1 \%$ [2]. The exponentially changing trend line reveals the critical situation in the region and suggests rapid intervention by those responsible.

Work limitation: It remains to be noted that the information found in the files is not enough for a more indepth socio-demographic study.

\section{Conclusion}

The results of our study made it possible to draw up an epidemiological profile of psychiatric disorders and to have an idea of the mental health of the population in the province of Taza (Morocco). Thus, providing a relevant reference for further research. The study also showed some characteristics of schizophrenic modulation that appear to be worrisome, so imposing more vigilance on the part of stakeholders in the field of public health in general and mental health.

This preliminary work will be used to launch further work to answer a series of questions about the impact of the environment, diet, and other parameters that were involved in triggering disease in the population.

\footnotetext{
Acknowledgements

The authors are indebted to the staff of the psychiatric service of Taza and: Ms. Hajar Hormattalah: Psychiatric infirmary for her active presence.

Dr: Asmae Tliji: Psychiatric doctor for her constant help.

Mr. Mouhamed TOUZANI, Health-Environment Service of the provincial delegation of Taza for his support.

Dr. Hamid Bensghir, doctor and provincial delegate for having given the agreement to carry out the study.
}

\begin{abstract}
Authors' contributions
$\mathrm{HL}$ : is a statistician who helped me to screw up my statistical tests. AK: a PhD student who corrected my French language before translating it into fertilizer and also helped me in the analysis of my experience. Hh: a psychiatric nurse who helped me a lot in collecting information from the cervical archives. AT: a psychiatric doctor who helped me to explain our results and she supported me during the whole period of the internship. AO: a member of our laboratory in charge of checking the writing. EA: director of our laboratory, he always gives his final opinion about the relevance of the results. EA: my thesis supervisor and guides me throughout my thesis. I am El Hassan Ouanouche and I declare that all the authors have read and
\end{abstract} approved the manuscript and I assume all my responsibility in this matter.

\section{Authors' information}

El hassan Ouanouche,40 years old, Moroccan nationality. Professor of life and earth sciences at the Ministry of Education. Doctoral student since 2015 at the Faculty of Science Ibn Tofail in Kenitra (Morocco). 


\section{Funding}

Not applicable.

\section{Availability of data and materials}

All data are available and archived at the Ibn Baja Psychiatry Department in the city of Taza (Morocco).

The data is collected anonymously and requires only the authorization of the provincial delegation, and I have authorization.

All databases are available from the author.

\section{Declarations}

\section{Ethics approval and consent to participate}

The procedures followed were in accordance with the ethical standards of the competent commission for human experimentation and the principles of the Declaration of Helsinki. Written informed consent was obtained from all participants and authorization from the ethics committee of the CED (CENTRE D'ETUDES DOCTORALES-FSK) of the Faculty of Science in Kenitra and the provincial delegation of the Ministry of Public Health 09/2015 in order to continue the study.

\section{Consent for publication}

Not applicable

\section{Competing interests}

The authors declare that they have no competing interests

\section{Author details}

'Biology and Health Laboratory, Department of Biology, Faculty of Sciences, University Ibn Tofail, FSK-Kenitra, Kenitra, Morocco. ${ }^{2}$ Laboratory of Genetic and Biometric, Department of Biology, Faculty of Science, Ibn Tofail University, Kenitra, Morocco. ${ }^{3}$ Department of Psychiatry, Ibn Baja Hospital, BP35000 Taza, Morocco.

Received: 8 May 2020 Accepted: 29 April 2021

Published online: 24 May 2021

\section{References}

1. Anderson GF, Chu E. Expanding priorities - confronting chronic disease in countries with low income. N Engl J Med. 2007;356(3):209-11. https://doi. org/10.1056/NEJMp068182.

2. Rouillon F. Epidemiology of psychiatric disorders; 2007.

3. Moussaoui D. La santé mentale au Maroc : enquête nationale sur la prévalence des troubles mentaux et des toxicomanies; 2007.

4. Boudef M, Ghouma D, Bennoua S. Les urgences psychiatriques : Profil épidémiologique. Rev Sante Plus. 1992;15.

5. Gregory Katz MD. A comparative study of psychiatric inpatients in a general hospital and a psychiatric hospital in Israel: demographics, psychopathological aspects and drug abuse patterns. IMAJ. 2011;13.

6. Le Fur P, Lorand S, Lucas-Gabrielli V. La morbidite' des patients pris en charge a' temps complet dans les secteurs de psychiatrie ge'ne' rale. In: Coldefy $M$, editor. La prise en charge de la sante' mentale. Paris: La documentation franc,aise, Collection E'tudes et Statistiques; 2007. p. 145-71.

7. Belghazi D, Moussaoui D, Kadri N. Epidemiological, clinical and cultural specificities of patients hospitalized in the Ibn-Rushd university psychiatric centre of Casablanca; 2013

8. Daoudi D, Tazi MA, Asouab F, Arrag M, Meski FZ, Khattabi A. Epidémiologie des troubles psychiatriques dans la Province de Kénitra, Maroc : une étude rétrospective sur 11 années; 2017.

9. El Emrani L, Bendriss A, Senhaji M. Santé et qualité de vie: situation pour la population de Tétouan; 2013.

10. Hernan A. Epidemiologic characteristic of bipolar patients admitted to the psychiatric clinic of the University of Chile. Blackwell publishing Itd. Bipolar Disord. 2006;8:1-68.

11. Kadri N, Agoub M, Assouab F, Tazi MA, Didouh A, Stewart R, et al. Moroccan national study on prevalence of mental disorders: a community-based epidemiological study. Acta Psychiatr Scand. 2010;121(1):71-4.

12. Peen J, Schoevers RA, Beekman AT, Dekker J. The current status of urban-rural differences in psychiatric disorders. Acta Psychiatr Scand. 2010;121(2):84-93.
13. Romans $\mathrm{S}$, Cohen $\mathrm{M}$, Forte $\mathrm{T}$. Rates of depression and anxiety in urban and rural Canada. Soc Psychiatry Psychiatr Epidemiol. 2011;46:567-75. https://doi. org/10.1007/s00127-010-0222-2.

14. Rouillon F. Guide pratique de psychiatrie.Coll. Mediguides, $2^{\circ}$ Ed. Masson; 2005. p. 157.

15. Kachouchi A, Sebbani M, Salim S, Adali I, Manoudi F, Amine M, et al. Facteurs de risque de passage à l'acte d'homicide chez des patients marocains atteints de schizophrénie; 2017.

16. Changa Q, Wub D, Rongb H, Wub Z, Taob W, Liub H, et al. Suicide ideation, suicide attempts, their sociodemographic and clinical associates among the elderly Chinese patients with schizophrenia spectrum disorders; 2019.

17. Ayoub M, Moussaoui D, Kadri N. Assessment of suicidality in a Moroccan metropolitan area. J Affect Disord. 2006;90(2):223-6.

18. Kelly BD, O'Callaghan E, Waddignton $J$, et al. Schizophrenia and the city: a review of literature and prospective study of psychosis and urbanicity in Ireland. Schizophr Res. 2010;116(1):75-89. https://doi.org/10.1016/j.schres.2 009.10.015.

19. Krabbendam L, Van Os J. Schizophrenia and urbanicity: a major environmental influence conditional on genetic risk. Schizophr Bull. 2005; 31(4):795-9. https://doi.org/10.1093/schbul/sbi060.

20. Gourier C, Chan Chee C, Beltzer N. Prévalence de la schizophrénie et autres troubles psychotiques en France métropolitaine; 2014.

\section{Publisher's Note}

Springer Nature remains neutral with regard to jurisdictional claims in published maps and institutional affiliations.

\section{Submit your manuscript to a SpringerOpen ${ }^{\circ}$ journal and benefit from:}

- Convenient online submission

- Rigorous peer review

- Open access: articles freely available online

- High visibility within the field

- Retaining the copyright to your article

Submit your next manuscript at $\boldsymbol{\nabla}$ springeropen.com 